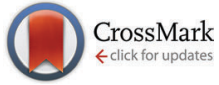

Cite this: Chem. Commun., 2015, 51, 6785

Received 5th February 2015 Accepted 10th March 2015

DOI: $10.1039 / c 5 c c 01083 g$

www.rsc.org/chemcomm

\title{
Dioxygenation of cysteamine to hypotaurine at a tris(pyrazolyl)borate iron(II) unit - cysteamine dioxygenase mimicking? + t
}

\author{
M. Sallmann, B. Braun and C. Limberg*
}

\begin{abstract}
A novel complex $\mathrm{Tp}^{\mathrm{Me}, \mathrm{Ph}} \mathrm{Fe}\left(\mathrm{SCH}_{2} \mathrm{CH}_{2} \mathrm{NH}_{2}\right)$ has been synthesized as a speculative model for ADO. Indeed its reaction with $\mathrm{O}_{2}$ led to the dioxygenation of the $S$ atom and thus to hypotaurine. This finding may allow us to draw conclusions on the constitution of the ADO active site, whose structure is still unknown.
\end{abstract}

Besides cysteine dioxygenase (CDO) the only other thiol dioxygenase active in mammals is cysteamine (2-aminoethanethiol) dioxygenase (ADO). ${ }^{1}$ It catalyses the dioxygenation of the thiol group in 2-aminoethanethiol released during co-enzyme A degradation with dioxygen to produce hypotaurine (Scheme 1).

The structure and mechanism of CDO has been intensely investigated within the last 10 years,$~^{2-8}$ whereas ADO has received comparatively little attention. It is known to be based on iron and to belong to the cupin family but apart from that many questions remain open with respect to its active site and functioning. ${ }^{1 a}$ The fact that CDO and ADO mediate a similar reaction setting out from a thiol substrate suggests that there is a phylogenetic connection between them. ${ }^{1,9}$

The CDO active site contains an iron centre surrounded by three facially arranged histidine ligands, and to this unit the S-deprotonated cysteine substrate then binds in a bidentate fashion via the amine and the thiolate functions, leaving one coordination site open for the coordination and activation of $\mathrm{O}_{2}{ }^{3}$ Through a complex mechanism the two $\mathrm{O}$ atoms are finally transferred to the sulfur atom yielding a cysteine sulfinic acid.

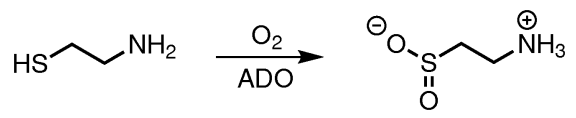

Scheme 1 Oxidation of cysteamine to hypotaurine catalyzed by ADO. ${ }^{1}$

Department of Chemistry, Humboldt-Universität zu Berlin, Brook-Taylor-Str. 2, 12489 Berlin, Germany. E-mail: christian.limberg@chemie.hu-berlin.de

$\dagger$ Dedicated to Professor Dr Manfred Scheer on the occasion of his 60th birthday. ‡ Electronic supplementary information (ESI) available: The method, synthesis and analysis as well as crystallographic data. CCDC 1044609. For ESI and crystallographic data in CIF or other electronic format see DOI: 10.1039/c5cc01083g
Modelling this reactivity with molecular compounds is complicated by the tendency of iron(II) thiolates to form $\mathrm{Fe}^{\mathrm{III}}$ $\mathrm{O}-\mathrm{Fe}^{\mathrm{III}}$ units and disulfanes upon addition of $\mathrm{O}_{2} \cdot{ }^{5}$ Nevertheless, research aimed at mimicking $\mathrm{CDO}$ has met with some success in recent years. ${ }^{5-8}$ After first reports by Goldberg and co-workers on the trioxygenation of thiolates coordinated to iron, ${ }^{5}$ we were able to report the successful coordination and dioxygenation of a protected cysteinato ligand at a (His) ${ }_{3} \mathrm{Fe}^{\mathrm{II}}$ analogue, namely a $\mathrm{Tp}^{\mathrm{Me}, \mathrm{Ph}} \mathrm{Fe}^{+}$complex metal fragment. ${ }^{7}$ To test the hypothesis that the $\mathrm{ADO}$ active site is related to that of $\mathrm{CDO}$, an investigation of the oxidation of cysteamine at the $\mathrm{Tp}^{\mathrm{Me}, \mathrm{Ph}} \mathrm{Fe}^{+}$scaffold thus suggested itself.

To synthesise a $\mathrm{Tp}^{\mathrm{Me}, \mathrm{Ph}} \mathrm{Fe}$-cysteamine complex a solution of 2-aminoethane thiol in dichloromethane was treated with triethylamine and subsequently a solution of $\mathrm{Tp}^{\mathrm{Me}, \mathrm{Ph}} \mathrm{FeCl}^{10}$ in the same solvent was added. After stirring for $12 \mathrm{~h}$ the work-up yielded a light yellow solid of pure $\mathrm{Tp}^{\mathrm{Me}, \mathrm{Ph}} \mathrm{Fe}\left(\mathrm{SCH}_{2} \mathrm{CH}_{2} \mathrm{NH}_{2}\right), \mathbf{1}$, in $43 \%$ yield (Scheme 2 ).

Through slow evaporation of the solvent from a solution of 1 in dichloromethane, crystals could be grown that were investigated via X-ray diffraction, and the result is shown in Fig. 1.

As expected S-deprotonated cysteamine coordinates as a chelating ligand, so that a distorted trigonal bipyramidal coordination sphere results for the iron(II) centre $(\tau=0.57)$. The Fe-S and Fe-N bond lengths of 2.3174(6) $\AA$ and 2.2520(18) $\AA$ differ only slightly from those found in the cysteine-based analogue. ${ }^{7}$ As in the latter, the iron centre is prepared for $\mathrm{O}_{2}$ binding and activation, since sufficient space remains open within its
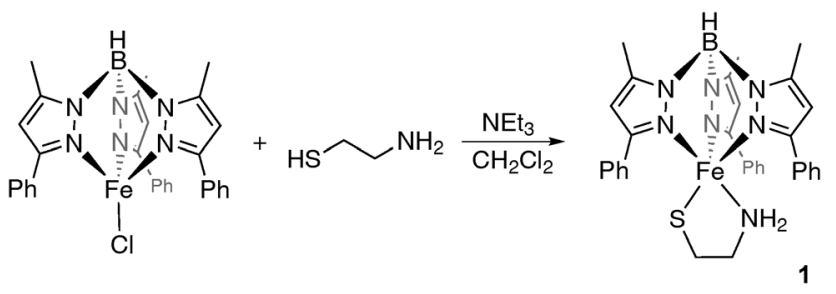

Scheme 2 Synthesis of $\left[\mathrm{Tp}^{\mathrm{Me}, \mathrm{Ph}} \mathrm{Fe}\left(\mathrm{SCH}_{2} \mathrm{CH}_{2} \mathrm{NH}_{2}\right)\right], 1$. 


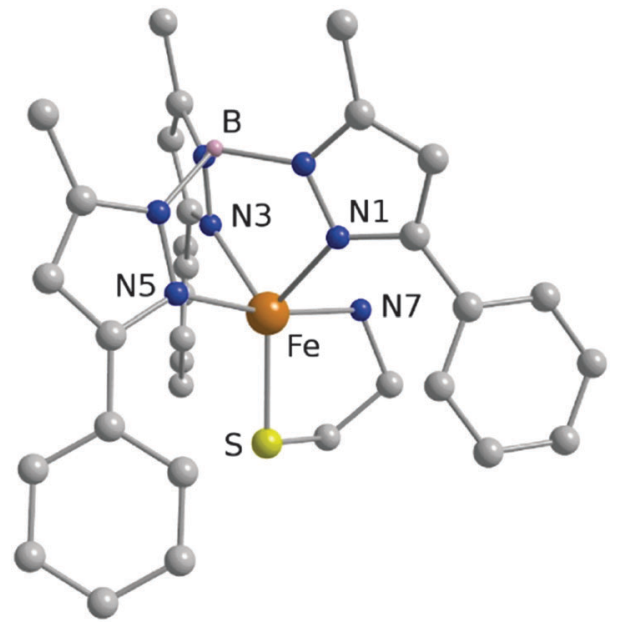

Fig. 1 Molecular structure of 1 (all hydrogen atoms have been omitted for clarity). Selected bond lengths ( $\AA$ ) and angles ( ${ }^{\circ}$ ): Fe-S 2.3174(6), $\mathrm{Fe}-\mathrm{N} 7$ 2.2520(18), Fe-N1 2.1531(16), Fe-N3 2.1102(16), Fe-N5 2.2489(16), and S-Fe-N7 84.96(5).

coordination sphere and it exists in its high-spin state: the effective magnetic moment of $\mathbf{1}$ as determined for a $\mathrm{C}_{6} \mathrm{D}_{6}$ solution by the Evans method at room temperature amounted to $5.36 \mu_{\mathrm{B}}$, which is close to the spin-only value expected for four unpaired electrons $\left(4.90 \mu_{\mathrm{B}}\right)$.

To investigate the reactivity of $\left[\mathrm{Tp}^{\mathrm{Me}, \mathrm{Ph}} \mathrm{Fe}\left(\mathrm{SCH}_{2} \mathrm{CH}_{2} \mathrm{NH}_{2}\right)\right]$ towards $\mathrm{O}_{2}$ a solution of $\mathbf{1}$ in dichloromethane was exposed to $\mathrm{O}_{2}$ under anhydrous conditions. Within $4 \mathrm{~h}$ a colour change from light yellow to dark green occurred that was monitored by UV/Vis spectroscopy (Fig. 2).

In the course of the reaction a shoulder found in the spectrum of $\left[\mathrm{Tp}^{\mathrm{Me}, \mathrm{Ph}} \mathrm{Fe}\left(\mathrm{SCH}_{2} \mathrm{CH}_{2} \mathrm{NH}_{2}\right)\right], \mathbf{1}$, at $360 \mathrm{~nm}\left(\varepsilon=231 \mathrm{M}^{-1} \mathrm{~cm}^{-1}\right)$, which may be assigned to a $\mathrm{S} \rightarrow$ Fe charge-transfer, loses in intensity and after $6 \mathrm{~h}$ it is vanished almost completely. A similar observation had been made in the case of the cysteinate complex, and it may indicate the cleavage of the Fe-S bond.

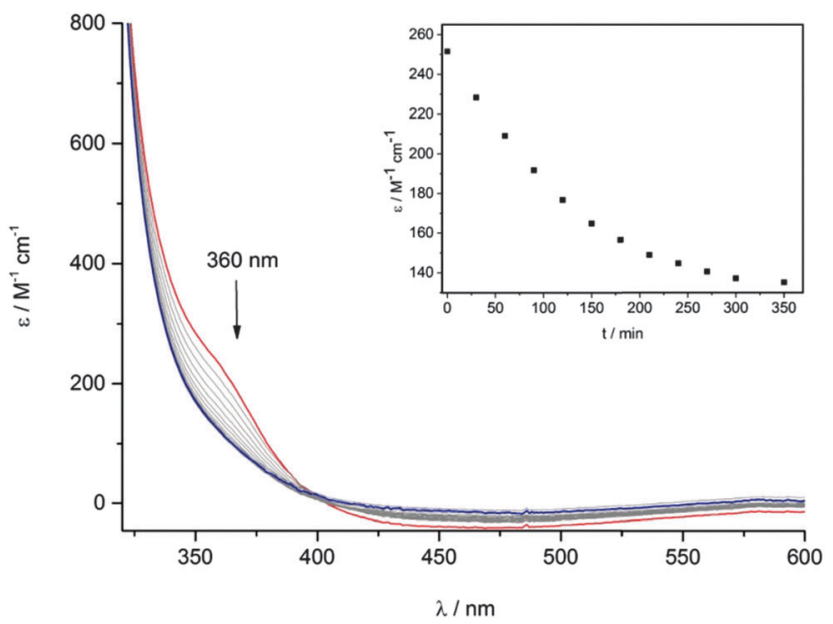

Fig. 2 UV/Vis spectral changes in course of the reaction of 1 (blue) dissolved in dichloromethane with $\mathrm{O}_{2}$ within $6 \mathrm{~h}$ (red); the inset shows the behaviour of the $360 \mathrm{~nm}$ absorbance with time.
The final reaction mixture was also investigated by ESI-MS. A dichloromethane solution of $\mathbf{1}$ gives rise to a major signal at $615.18 \mathrm{~m} / \mathrm{z}$ corresponding to $[\mathbf{1}]^{+}$as well as to a signal at $638.18 \mathrm{~m} / \mathrm{z}$ assigned to the $\mathrm{Na}^{+}$adduct of $\mathbf{1}$ (see ESI + ). After $\mathrm{O}_{2}$ treatment two new signals were observed at $670.17 \mathrm{~m} / \mathrm{z}$, matching the spectrum calculated for $\left[\left(1+\mathrm{O}_{2}\right)+\mathrm{Na}\right]^{+}$, as well as a signal at $685.16 \mathrm{~m} / \mathrm{z}$ belonging to the corresponding $\mathrm{K}^{+}$analogue (as for sodium ions, potassium ions from the environment are also sometimes observed to form adducts $\left.{ }^{7}\right)$. To confirm these assignments, experiments with ${ }^{18} \mathrm{O}$-enriched dioxygen (99\%) were also performed. In the ESI-TOF spectrum recorded subsequently from the reaction solution, a shift of the $\left[\left(1+\mathrm{O}_{2}\right)+\mathrm{Na}\right]^{+}$peak by four mass units to $674.18 \mathrm{~m} / z$ could be observed, indicating that in the course of the reaction with $\mathrm{O}_{2}$, two $\mathrm{O}$ atoms are incorporated, that is, a dioxygenation takes place (see ESI\$). Under the more dilute conditions of the ${ }^{18} \mathrm{O}_{2}$ experiment additionally a signal at $697.25 \mathrm{~m} / \mathrm{z}$ appeared, which could not be assigned. It sometimes was also observed in the ${ }^{16} \mathrm{O}_{2}$ experiments and thus does not belong to an oxygenation product.

Recording an EPR spectrum of the final product mixture in the perpendicular mode did not reveal any signal, that is, the sample is EPR silent, as one would expect for a product complex with iron in the oxidation state + II.

To demonstrate that the dioxygenation occurs selectively at the cysteamine ligand, a work-up procedure was developed for the reaction mixture, which finally allowed for the isolation of the cysteamine part of the reaction product. First of all three compounds were conceivable and had to be distinguished: (a) cysteamine in the case of selective oxygenation of the Tp ligand, (b) the sulfinic acid hypotaurine after selective dioxygenation of the cysteamine ligand and (c) the corresponding sulfenic acid as a product of monooxygenation. Beyond that, two other products had to be considered, although these are not in agreement with the ESI-TOF results: SS-bond formation, which often occurs upon coordination of thiolates to highly oxidized metal centres, leads to the disulphide (e), a triple-oxygenation, as observed in the case of some models for the CDO reported in the literature, ${ }^{5,6}$ to taurine (d), as shown in Scheme 3.

The work-up of the reaction mixture was performed by addition of $3 \mathrm{M}$ hydrochloric acid as well as chelex in $\mathrm{MeOH}$ to separate all iron ions, and washing with toluene removed the decomposition product of Tp. The investigation of all residual

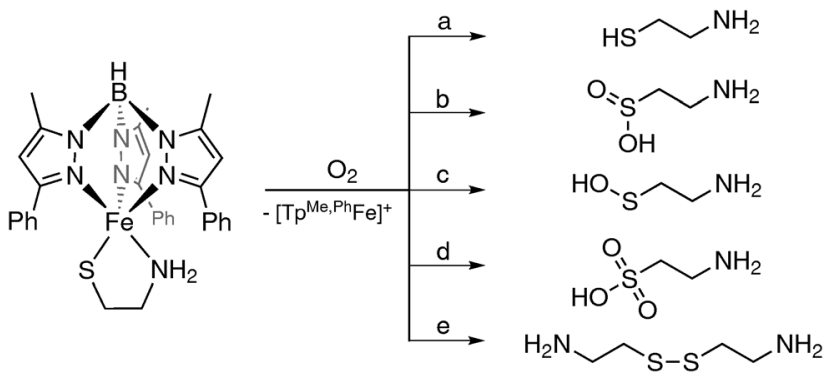

Scheme 3 The reaction of 1 with $\mathrm{O}_{2}$ and conceivable products resulting from work-up: cysteamine (a), hypotaurine (b), 2-aminoethanesulfenic acid (c), taurine (d) and cystamine (e). 


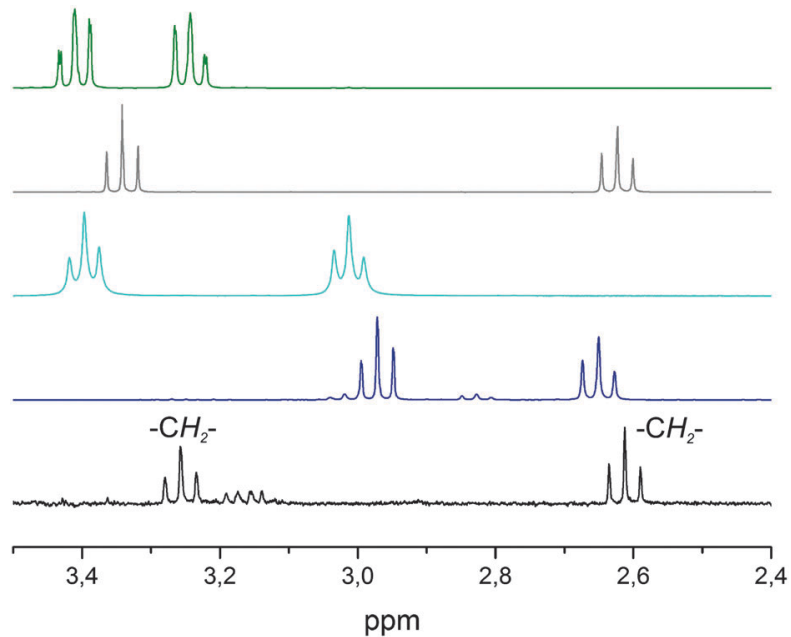

Fig. 3 Comparison of the ${ }^{1} \mathrm{H}-\mathrm{NMR}$ spectra of the isolated oxidation product (black), cysteamine (dark blue), cystamine (light blue), hypotaurine (grey) and taurine (green) dissolved in $\mathrm{D}_{2} \mathrm{O}$.

organic components was performed by ${ }^{1} \mathrm{H}$ NMR spectroscopy, and the spectrum obtained was then compared with the spectra of cysteamine, hypotaurine, taurine and cystamine, all of which feature two (pseudo) triplets at characteristic chemical shifts (see Fig. 3).

Clearly, the spectrum of hypotaurine fitted best to the one recorded after work-up, although the low-field triplet occurred shifted by $0.09 \mathrm{ppm}$ to higher field. To test whether impurities like residual iron ions are responsible for this shift, commercially obtained hypotaurine was added to the sample of the oxygenation product, and as still only one signal set was observed afterwards, it thus became clear that hypotaurine is indeed the dioxygenation product. Consequently, the reaction of 1 with $\mathrm{O}_{2}$ leads to the product $\left[\mathrm{Tp}^{\mathrm{Me}, \mathrm{Ph}} \mathrm{Fe}\left(\mathrm{O}_{2} \mathrm{SCH}_{2} \mathrm{CH}_{2} \mathrm{NH}_{2}\right)\right], 2$. Due to the instability of 2 all attempts to grow single crystals that might have allowed the characterization via X-ray diffraction have failed so far.

Altogether the results suggest the following logic operation: the active site structure of ADO is still unknown but it may resemble that of $\mathrm{CDO}$, which shows rather similar reactivity. The active centre of CDO contains an iron(II) ion coordinated by three histidine residues, which binds the cysteine in a chelating fashion. In previous work a $\mathrm{TpFe}^{\mathrm{II}}$ complex with a cysteinate ethyl ester ligand proved capable of mimicking the CDO both structurally and functionally. ${ }^{7}$ Hence, in this work a complex $\mathrm{Tp}^{\mathrm{Me}, \mathrm{Ph}} \mathrm{Fe}\left(\mathrm{SCH}_{2} \mathrm{CH}_{2} \mathrm{NH}_{2}\right), \mathbf{1}$, has been synthesized as a speculative model for $\mathrm{ADO}$. Indeed its reaction with $\mathrm{O}_{2}$ led to the dioxygenation of the $\mathrm{S}$ atom and thus to hypotaurine. This result lends further support to the hypothesis that the active sites of CDO and ADO are quite similar.

We are grateful to the Humboldt-Universität zu Berlin for financial support. We also thank the Cluster of Excellence "Unifying Concepts in Catalysis" funded by the DFG for helpful discussions.

\section{Notes and references}

1 (a) J. E. Dominy, Jr., C. R. Simmons, L. L. Hirschberger, J. Hwang, R. M. Coloso and M. H. Stipanuk, J. Biol. Chem., 2007, 282, 25189-25198; (b) beyond that two bacterial homologues of CDO were identified, which catalyse the oxidation of 3-mercaptopropionate: J. E. Dominy Jr., C. R. Simmons, L. L. Hirschberger, J. Hwang, R. M. Coloso and M. H. Stipanuk, J. Biol. Chem., 2007, 282, 25189.

2 J. G. McCoy, L. J. Bailey, E. Bitto, C. A. Bingman, D. J. Aceti, B. G. Fox and G. N. Phillips, Jr., Proc. Natl. Acad. Sci. U. S. A., 2006, 103, 3084-3089.

3 S. Ye, X. Wu, L. Wei, D. Tang, P. Sun, M. Bartlam and Z. Rao, J. Biol. Chem., 2007, 282, 3391-3402.

4 S. Aluri and S. P. de Visser, J. Am. Chem. Soc., 2007, 129, 14846-14847.

5 Y. Jiang, L. R. Widger, G. D. Kasper, M. A. Siegler and D. P. Goldberg, J. Am. Chem. Soc., 2010, 132, 12214-12215.

6 Y. M. Badiei, M. A. Siegler and D. P. Goldberg, J. Am. Chem. Soc., 2011, 133, 1274-1277.

7 M. Sallmann, I. Siewert, L. Fohlmeister, C. Limberg and C. Knispel, Angew. Chem., 2012, 124, 2277-2280 (Angew. Chem., Int. Ed., 2012, 51, 2234-2237).

8 A. C. McQuilken, Y. Jiang, M. A. Siegler and D. P. Goldberg, J. Am. Chem. Soc., 2012, 134, 8758-8761.

9 D. Buongiorno and G. D. Straganz, Coord. Chem. Rev., 2013, 257, 541-563.

10 T. Tietz, C. Limberg, R. Stößer and B. Ziemer, Chem. - Eur. J., 2011, 17, 10010-10020. 